\title{
Article
}

\section{Preliminary SAR on indole-3-carbinol and related fragments reveals a novel anticancer lead compound against resistant glioblastoma cells}

Sherer, Christopher, Tolaymat, Ibrahim, Rowther, Farzana, Warr, Tracy and Snape, Timothy James

Available at http://clok.uclan.ac.uk/17152/

Sherer, Christopher ORCID: 0000-0002-6422-9870, Tolaymat, Ibrahim, Rowther, Farzana, Warr, Tracy and Snape, Timothy James ORCID: 0000-00032766-4491 (2017) Preliminary SAR on indole-3-carbinol and related fragments reveals a novel anticancer lead compound against resistant glioblastoma cells. Bioorganic \& Medicinal Chemistry Letters, 27 (7). pp. 1561-1565. ISSN 0960-894X

It is advisable to refer to the publisher's version if you intend to cite from the work. http://dx.doi.org/10.1016/j.bmcl.2017.02.033

For more information about UCLan's research in this area go to http://www.uclan.ac.uk/researchgroups/ and search for < name of research Group>.

For information about Research generally at UCLan please go to http://www.uclan.ac.uk/research/

All outputs in CLoK are protected by Intellectual Property Rights law, including Copyright law. Copyright, IPR and Moral Rights for the works on this site are retained by the individual authors and/or other copyright owners. Terms and conditions for use of this material are defined in the policies page. 


\section{Accepted Manuscript}

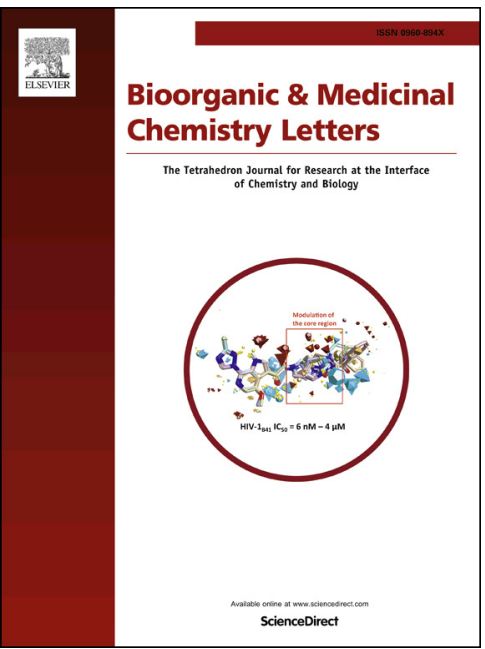

Preliminary SAR on indole-3-carbinol and related fragments reveals a novel anticancer lead compound against resistant glioblastoma cells

Christopher Sherer, Ibrahim Tolaymat, Farzana Rowther, Tracy Warr, Timothy J. Snape

PII: S0960-894X(17)30167-1

DOI: http://dx.doi.org/10.1016/j.bmcl.2017.02.033

Reference: BMCL 24705

To appear in:

Bioorganic \& Medicinal Chemistry Letters

Received Date:

29 November 2016

Revised Date:

14 February 2017

Accepted Date:

15 February 2017

Please cite this article as: Sherer, C., Tolaymat, I., Rowther, F., Warr, T., Snape, T.J., Preliminary SAR on indole-3carbinol and related fragments reveals a novel anticancer lead compound against resistant glioblastoma cells, Bioorganic \& Medicinal Chemistry Letters (2017), doi: http://dx.doi.org/10.1016/j.bmcl.2017.02.033

This is a PDF file of an unedited manuscript that has been accepted for publication. As a service to our customers we are providing this early version of the manuscript. The manuscript will undergo copyediting, typesetting, and review of the resulting proof before it is published in its final form. Please note that during the production process errors may be discovered which could affect the content, and all legal disclaimers that apply to the journal pertain. 
Preliminary SAR on indole-3-carbinol and related fragments reveals a novel anticancer lead compound against resistant glioblastoma cells

Christopher Sherer, ${ }^{\mathrm{a}}$ Ibrahim Tolaymat, ${ }^{\mathrm{b}}$ Farzana Rowther, ${ }^{\mathrm{c}}$ Tracy Warr, ${ }^{\mathrm{c}}$ Timothy J. Snape*,a

${ }^{a}$ School of Pharmacy and Biomedical Sciences, University of Central Lancashire, Maudland Building, Preston, Lancashire, PR1 2HE, UK. ${ }^{\mathrm{b}}$ Faculty of Medical Science, Anglia Ruskin University, Bishop Hall Lane, Chelmsford, Essex, CM1 1SQ, UK. ${ }^{c}$ Brain Tumour Research Centre, University of Wolverhampton, Wulfruna Street, Wolverhampton, WV1 1LY, UK.

Keywords: indole-3-carbinol; 3,3'-diindoloylmethane; glioblastoma; cancer; SAR

Abstract: The prognosis for glioblastoma patients is, at best, poor, with the median time of survival after diagnosis measured in months. As such, there is much need for the rapid development of potent and novel treatments. Herein, we report our preliminary findings on the SAR of a series of indole-3-carbinol and related fragments and reveal a potent lead with low micromolar activity against a particularly resistant glioblastoma cell culture, providing a new platform for future development of a new therapy in this area.

Glioblastoma are the most common form of malignant brain tumours in adults and account for $12-15 \%$ of all primary intracranial neoplasms. They are aggressive, often resistant to treatment and primarily affect adults aged between 45 and 75 years old. The median survival time is 6 months with only $28 \%$ of glioblastoma patients surviving more than one year, and only $3 \%$ of patients surviving more than three years. ${ }^{1}$ Undoubtedly, the prognosis is poor, and whilst the standard best treatment procedure is currently maximal safe surgical resection followed by simultaneous radiotherapy to the resection site and chemotherapy with temozolomide, in what is referred to as the "Stupp protocol", this regimen merely leads to a mean survival of 14.6 months and a two year survival of $26.5 \%$. $^{2}$ As such, glioblastoma are largely considered to be currently incurable. Such stark statistics highlight a much needed investment in the research surrounding treatment, not only to improve survival times per se, but survival with an excellent quality of life.

Several years ago, we proposed that indoles (1 and 2) may be considered to be hybrid structures between the naturally occurring anticancer compound indole-3-carbinol (I3C, 3) 
and the known privileged structure 2-phenylindole (4, Figure 1), and have shown that the "hybrid" structure $\mathbf{1}$ possesses modest anticancer activity against glioblastoma cell lines and short term cultures, whilst $\mathbf{2}$, although more active against these cultures, has been too unstable to enable further study. ${ }^{3}$ However, recent studies into the mechanism of action of $\mathbf{1}$ have suggested that the precise biological mechanisms of action of the two hybrid structures (1 and 2) may in fact be different, ${ }^{4}$ suggesting that, at least from a mechanistic point of view, these indoles are not hybrid structures, but should be treated as different compound classes, both of which happen to possess activity against glioma cell cultures. Herein, this study outlines the preliminary work carried out into I3C (3) and its derivatives (5) and highlights some important findings which have led to new lead compounds for future development into glioblastoma chemotherapies.

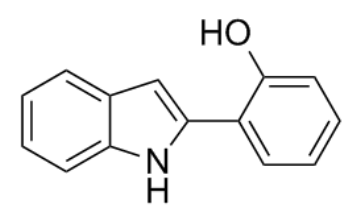

1<smiles>OCc1c[nH]c2ccccc12</smiles>

Indole-3-carbinol (I3C), 3<smiles>OCc1c(-c2ccccc2)[nH]c2ccccc12</smiles>

2<smiles>c1ccc(-c2cc3ccccc3[nH]2)cc1</smiles>

2-Phenylindole, 4

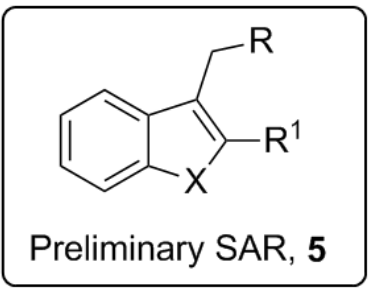

Preliminary SAR, 5

Figure 1 The structures of 1-4 and the Markush structure (5) showing the preliminary SAR investigated. For R, $\mathrm{R}^{1}$ and $\mathrm{X}-$ see Figure 3 .

Indole-3-carbinol $(\mathrm{I} 3 \mathrm{C}, 3)$ is found naturally in particularly high concentrations in cruciferous vegetables such as cabbage, kale, cauliflower and sprouts and is by far the most studied component of such vegetables, a class of plant that appears to contain many anticancer agents. ${ }^{5}$ In vitro and in vivo, I3C forms many degradation products (Figure 2), ${ }^{6}$ and their formation and properties have been an active area of study for over 30 years. ${ }^{7,8}$ During this time, I3C has been shown to be active against a wide variety of cancers, including breast, ${ }^{9}$ colon, ${ }^{10}$ prostate, ${ }^{11,12}$ and most recently by us, against glioblastoma. ${ }^{3}$ Many of I3C's metabolites have also been shown to have wide ranging effects in biological assays. ${ }^{11-13}$ Furthermore, Fang and co-workers have elegantly shown that small molecule derivatives of 
I3C possess antitumour activity through the modulation of functions in multiple cancerrelated pathways and are highly active in a subset of cancer cell lines from the National Cancer Institute (NCI-60) panel. However, it has been commented by those authors that the mechanism underlying the selective activity of their best $\mathrm{I} 3 \mathrm{C}$ derivative remains uncharacterised. ${ }^{14,15}$

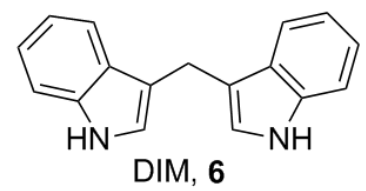<smiles>c1ccc2c(c1)[nH]c1cc3c(cc12)[nH]c1ccccc13</smiles>

ICZ

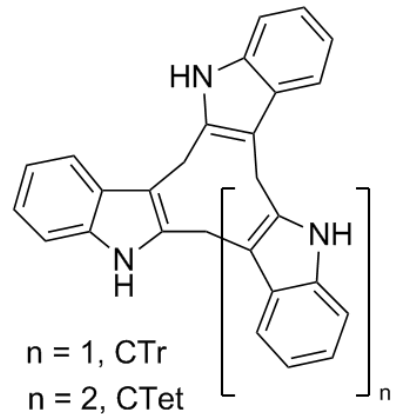

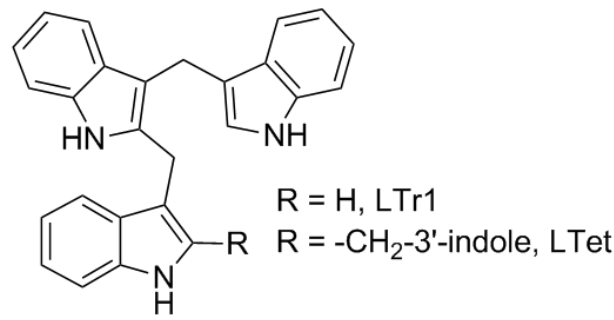

Figure 2 The known metabolites/degradation products of indole-3-carbinol: 3,3'-diindolylmethane (DIM, 6), a cyclic tetramer (CTet), the first linear trimer (LTr1), indolo[3,2-b]carbazole (ICZ), a cyclic trimer (CTr) and a linear tetramer (LTet).

The simplest and mostly widely studied I3C metabolite is 3,3'-diindolylmethane (DIM, 6). The mechanism for the conversion of I3C to DIM is well known, and proceeds under very mild acidic conditions via a 3 -methyleneindolinium intermediate $(7$, Scheme 1$){ }^{7}$ Based on this mechanism, DIM is known to be an active form of the prodrug $\mathrm{I} 3 \mathrm{C},{ }^{16}$ and is formed from I3C rapidly under the conditions of the stomach. ${ }^{17,18}$

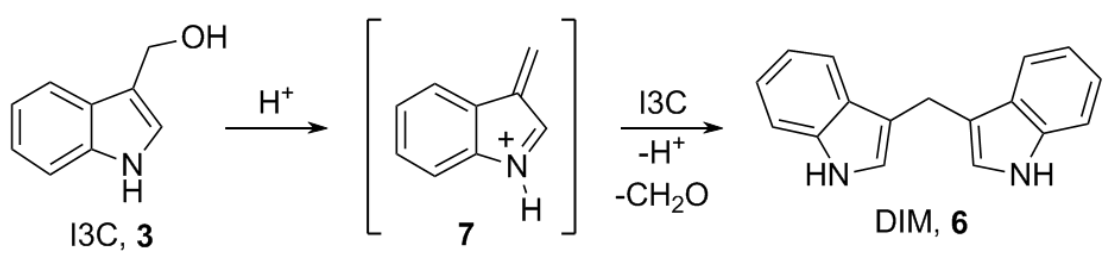

Scheme 1 The acid-catalysed conversion of I3C into DIM.

In vitro it is believed that $\mathrm{I} 3 \mathrm{C}$ is first converted into a cysteine-adduct, which is taken up by the cell and passed into the nucleus, where it is converted into DIM. It has been shown that I3C doesn't appear to exist in significant concentrations inside the cell at all, suggesting that 
$\mathrm{I} 3 \mathrm{C}$ is not directly responsible for any biological effects, and instead it is a metabolite of I3C that is the important active species. ${ }^{17}$

Previously, compound $\mathbf{2}$ was shown to be a marked improvement over its parent compound, I3C (3), against the U87 glioblastoma cell line, where $\mathrm{I} 3 \mathrm{C}$ had an $\mathrm{IC}_{50}$ of $526 \mu \mathrm{M}$, whereas compound 2 has an $\mathrm{IC}_{50}$ of $176 \mu \mathrm{M}$, an effect that was ascribed to the presence of the 2phenyl group in $\mathbf{2}^{3}$

Based on these observations, and in conjunction with our own recent findings, it is now evident that compounds $\mathbf{1}$ and $\mathbf{2}$ cannot be part of the same pharmacological class when compared in their entirety. Comparing the structure of a prodrug (2) to the structure of $\mathbf{1}$ is not evaluating like for like, and it is more appropriate to compare the structure of $\mathbf{1}$ with the active species DIM (or DIM analogue), which obviously share fewer structural features, and would therefore be unlikely to be considered as two members of the same chemical class.

\section{Preliminary SAR of fragments}

\section{The 3-carbinol group}

The 3-carbinol group of $\mathrm{I} 3 \mathrm{C}$ is considered an important feature for biological activity due to its role in the degradation to the active species, DIM. Its mechanism involving the loss of water and concomitant stabilisation of the carbocation through conjugation can be seen in Scheme 1. Consequently, by extending the carbon chain from hydroxymethane to hydroxyethane, thus no longer having the hydroxyl group conjugated with an electronegative atom on which the positive charge can rest, should prevent the formation of the active dimer, and biological activity would be reduced. Likewise, by the same argument, indole and 2-phenylindole should also be less active since they have no 3-substituent and thus a 3,3'diindolylmethane metabolic product cannot be formed. 


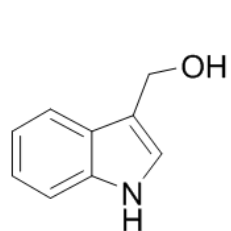

I3C, 3

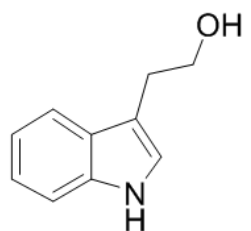

8

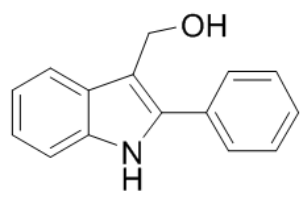

2

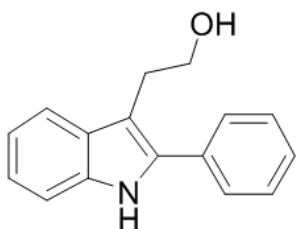

9<smiles>CC(=O)n1c(-c2ccccc2)c(CO)c2ccccc21</smiles>

10

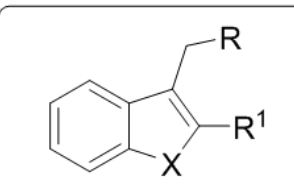

Preliminary SAR, 5<smiles></smiles>

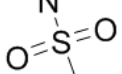
11

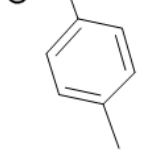

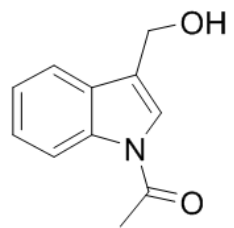

12

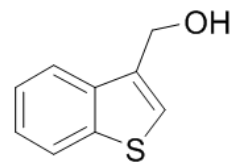

13

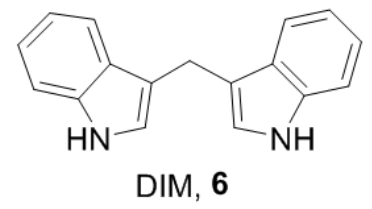

DIM, 6

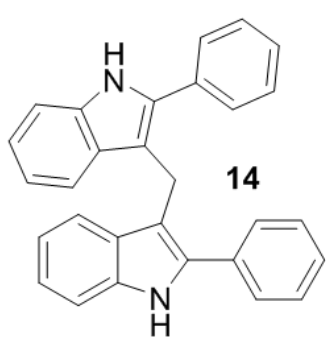

Figure 3 SAR studied, grouped by feature being investigated.

In relation to two established glioblastoma cell lines (U87, U251) and three short-term glioblastoma cultures (IN1472, IN1528, IN1760) against which the compounds were tested, indole itself and 2-phenylindole (4) had $\mathrm{EC}_{50}$ values that were too high to calculate based on the concentration ranges used (entries 1 and 4), suggesting a lack of activity in glioblastoma for these compounds. However, compound 2 was shown to have $\mathrm{EC}_{50}$ values in the range of $10-1430 \mu \mathrm{M}$, demonstrating a large increase in activity upon inclusion of the 3-carbinol group (compare entries 2 and 4), results which were supported by the data for indole vs. I3C $\left(\mathrm{EC}_{50}(\mathrm{I} 3 \mathrm{C})=119-1580 \mu \mathrm{M}\right.$, entries 1 and 3$)$.

Table 1 Comparison of $\mathrm{EC}_{50}$ values $(\mu \mathrm{M})$.

$\begin{array}{ccccccc}\text { Entry } & \text { Compound } & \begin{array}{c}\text { U87 } \\ (\boldsymbol{\mu M})\end{array} & \begin{array}{c}\mathbf{U 2 5 1} \\ (\boldsymbol{\mu M})\end{array} & \begin{array}{c}\text { IN1472 } \\ (\boldsymbol{\mu M})\end{array} & \begin{array}{c}\text { IN1528 } \\ (\boldsymbol{\mu M})\end{array} & \begin{array}{c}\text { IN1760 } \\ (\boldsymbol{\mu M})\end{array} \\ 1 & \text { indole }^{\mathrm{a}, \mathrm{b}} & - & - & - & - & - \\ 2 & \mathbf{2}^{\mathrm{b}} & 30 \pm 8 & 130 \pm 15 & 480 \pm 7 & 10 \pm 8 & 1430 \pm 394 \\ 3 & \text { I3C }, \mathbf{3}^{\mathrm{b}} & 290 \pm 19 & 390 \pm 5 & 950 \pm 232 & 119 \pm 6 & 1580 \pm 438\end{array}$




\begin{tabular}{|c|c|c|c|c|c|c|}
\hline 4 & $4^{\mathrm{a}, \mathrm{b}}$ & - & - & - & - & - \\
\hline 5 & DIM, $\mathbf{6}^{\mathrm{b}, \mathrm{c}}$ & - & $280 \pm 5$ & - & $440 \pm 153$ & $230 \pm 98$ \\
\hline 6 & $8^{\mathrm{b}}$ & $580 \pm 71$ & $1220 \pm 82$ & $\begin{array}{c}1950 \pm \\
268\end{array}$ & $1740 \pm 198$ & $4570 \pm 767$ \\
\hline 7 & 9 & $110 \pm 9$ & $250 \pm 37$ & $350 \pm 27$ & $4 \pm 1$ & $330 \pm 62$ \\
\hline 8 & $10^{\mathrm{c}}$ & - & $600 \pm 280$ & - & $>10000$ & $>10000$ \\
\hline 9 & $11^{\mathrm{c}}$ & - & $140 \pm 13$ & - & $440 \pm 60$ & $650 \pm 79$ \\
\hline 10 & $12^{\mathrm{c}}$ & - & $1760 \pm 10$ & - & $5820 \pm 260$ & $>10000$ \\
\hline 11 & $13^{\mathrm{c}}$ & - & $1240 \pm 172$ & - & $3990 \pm 526$ & $1080 \pm 139$ \\
\hline 12 & $14^{\mathrm{c}}$ & - & $50 \pm 8$ & & $270 \pm 35$ & $50 \pm 17$ \\
\hline
\end{tabular}

Extension of the 3-carbinol group (entries 6 and 7) yields less conclusive results. Comparing I3C with its hydroxyethane analogue 8 (entries 3 and 6) shows that 8 has consistently worse activity across all five cell lines and cultures on which they were tested. However, the 2phenyl analogues (2 and 9, entries 2 and 7) show much less consistency, with compound 2 having better activity against the two established cell lines U87 and U251, whereas its hydroxyethyl analogue (9) has better activity against the three short term cultures IN1472, IN1528 and IN1760, and is particularly active against IN1528 $\left(\mathrm{EC}_{50}=4 \mu \mathrm{M}\right)$. That said, when comparing $\mathbf{2}$ with $\mathbf{3}$, and $\mathbf{8}$ with $\mathbf{9}$, with respect to the 2-phenyl group, it is evident that the phenyl ring increases efficacy across all cells lines and cultures studied.

\section{The effect of $\mathrm{N}$-substituents}

Since a cationic intermediate $(7$, Scheme 1$)$ is involved in the conversion of I3C to its active form, DIM, the stability of this intermediate presumably impacts on the amount of DIM produced in vitro. Therefore, by increasing the stability of intermediate 7 sufficiently to enable dimerisation to occur, the yield of DIM should increase, and the observed anticancer 
activity should also increase accordingly. Conversely, destabilising the cation should result in lower anticancer activity since the formation of the intermediate (and hence dimer) would be retarded. Three analogues were produced in order to probe this hypothesis (Figure 3, 10-12). Two $\mathrm{N}$-substituents were chosen which are both electron withdrawing groups but to differing extents (the acetyl group being much less electron withdrawing than the tosyl group), structural features which should impact upon the rate of formation of cation 7, and thus anticancer activity. Acetyl groups are known to be hydrolysable and so could be expected to be cleaved in the cell, especially in the presence of numerous cellular proteases. However, the rate of hydrolysis compared to the rate of dimerisation would determine in which order these two processes would be likely to occur. For example, if the acetyl group is removed too easily (Scheme $2, \mathrm{k}_{1 \mathrm{Hydrol}}>>\mathrm{k}_{1 \mathrm{Dim}}$ ), then $\mathrm{I} 3 \mathrm{C}$ would be readily formed and the rate of dimerisation would likely be the same as the rate of dimerisation of $\mathrm{I} 3 \mathrm{C}$, so no difference in activity would be expected when comparing 12 to I3C. However, if the acetyl group is sufficiently stable, it should retard the rate of formation of the dimer (based on the mechanism shown in Scheme 1), which should also result in a reduced activity. These competing pathways are shown in Scheme 2.

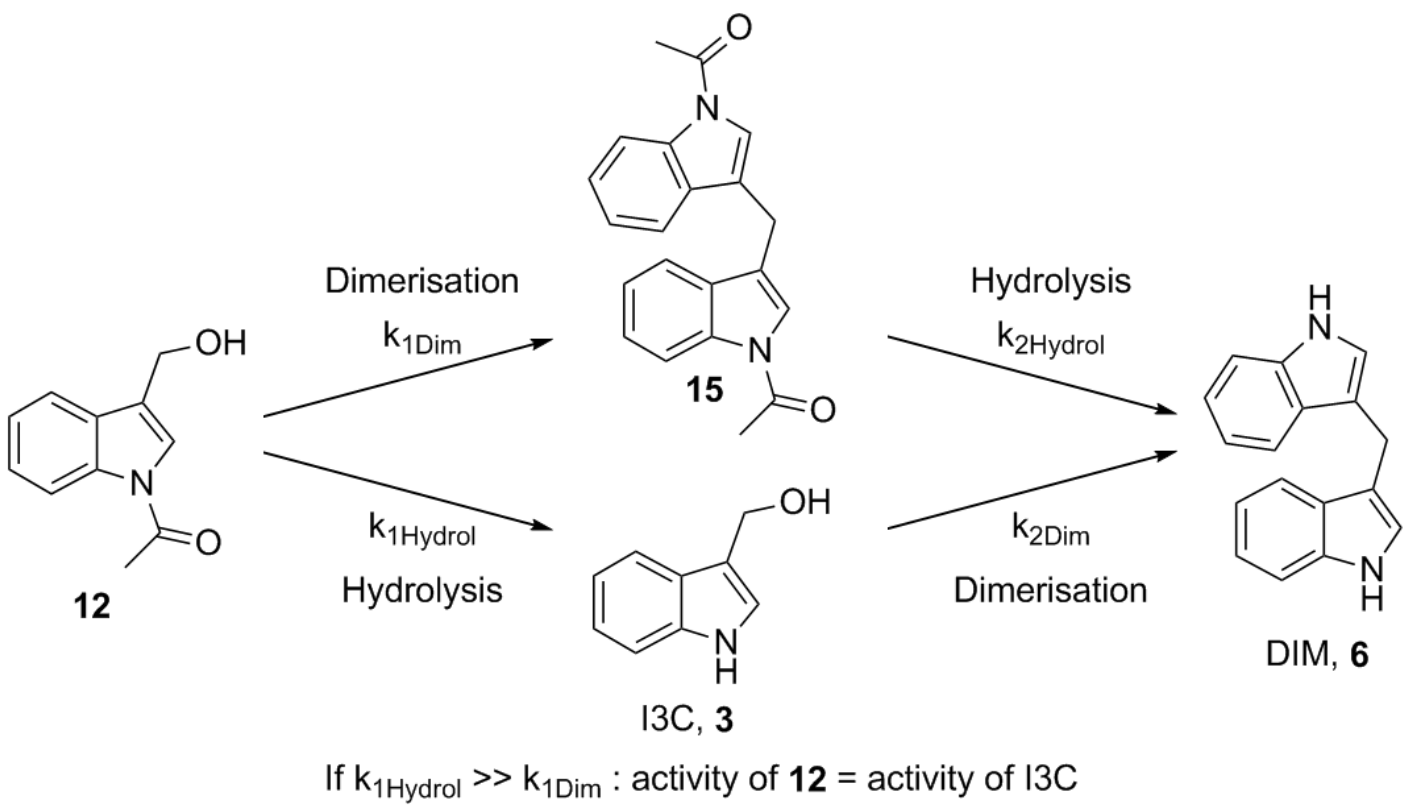

Scheme 2 The two potential pathways to DIM from compound $\mathbf{1 2 .}$

To ascertain if the inclusion of a hydrolysable group is significant in these compounds, an analogue containing a non-hydrolysable $N$-substituent should be included for comparison. 
This non-hydrolysable group should be as chemically similar as possible to the acetyl group in order to keep the analogue as otherwise similar. Therefore, the group should have electron withdrawing mesomeric properties, be relatively small, and be a hydrogen bond acceptor. A substituent that fulfils all of these criteria is the tosyl group. As such, the $N$-tosyl and $N$-acetyl analogues of I3C (compounds 11 and 12 respectively, shown in Figure 3) were synthesised and tested as direct comparisons to $\mathrm{I} 3 \mathrm{C}$, in addition to the $\mathrm{N}$-acetyl analogue of $\mathbf{2}$, namely compound 10.

When screened against the glioblastoma cell cultures (U251, IN1528 and IN1760), the effect of the $\mathrm{N}$-acetyl group shows a clear negative effect on anticancer activity, with both I3C and compound $\mathbf{2}$ (entries 2 and 3) having better activity than their $N$-acetyl analogues $\mathbf{1 0}$ and $\mathbf{1 2}$ (entries 8 and 10). Based on the established prodrug nature of I3C to convert to its active DIM form in biological assays, these results imply that the acetyl group is not effectively removed, either by hydrolysis or by enzymatic activity, and the formation of the dimer, through a mechanism similar to that shown in Scheme 1, is prevented. That said, it cannot be ruled out that the role of the $\mathrm{NH}$ group is important for binding, or that, through $\mathrm{N}$ substitution, the ability of the compounds to directly bind to cellular targets in their "prodrug" form has been altered.

Conversely, an improvement in activity was noted between I3C and its $N$-tosyl analogue 11 (entries 3 and 9) against U251 and IN1760. This was somewhat unexpected, since an electron withdrawing group on nitrogen should destabilise the intermediate cation, therefore reducing the amount of the resultant diindolylmethane formed, as seen with the $\mathrm{N}$-acetyl derivatives. However, despite this contradictory behaviour, these findings agree with Chen et al. who show that $N$-sulfonyl analogues of I3C have a significant improvement in activity compared to $\mathrm{I} 3 \mathrm{C}$ itself when studied against prostate cancer cell lines, and that in addition to chemical stability, the $\mathrm{N}$-tosyl group's unique stereoelectronic properties allowed their lead compound to interact more effectively with target proteins compared with indole-3-carbinol; all analogous amide derivatives tested were inactive in Chen's assays. ${ }^{19}$

From these results, it seems apparent that $N$-substitution alone is not simply an electronic change, but that the specific substituent itself may have a more complicated effect. Such an effect may be related to the ability of the prodrug to form the active dimer, the interaction of the $N$-substituent with a protein, or the solubility and uptake of either the prodrug or active compound. The fact that the effect of the two $N$-substituents on these fragments is so distinct 
(entries 8, 9 and 10) suggests that this position would be a viable option to investigate further, especially since some selectivity between cell types can be observed. ${ }^{14,15}$

\section{The heteroaromatic core}

An alternative way of affecting the electronic environment at positon- 1 of $\mathrm{I} 3 \mathrm{C}$ is to change the heteroatom completely. The analogous heteroaromatic systems benzofuran and benzothiophene lack a hydrogen at position-1, which may be significant, since the potential for this hydrogen to be abstracted from the cationic intermediate may lead to a significant stabilisation of the 3-methyleneindolinium intermediate (7) during the metabolism of I3C to DIM. In addition, benzofuran contains the more electronegative oxygen in place of a nitrogen, which would therefore lead to a less readily-formed (less stable) cationic intermediate. Conversely, since sulfur is less electronegative than nitrogen, the formation of a cationic intermediate from a benzothiophene analogue would be less difficult. That said, to our knowledge, there are no occurrences of an S or O equivalent of the dimerisation outlined in Scheme 1. Moreover, potentially important hydrogen-bond donor interactions will be lost when replacing $\mathrm{NH}$ with either $\mathrm{O}$ or $\mathrm{S}$, all features which should impact on biological activity. As a result of these potentially complex factors, the choice between testing a benzofuran or benzothiophene analogue became fairly arbitrary, and the decision to synthesise the benzothiophene analogue $\mathbf{1 3}$ for testing was ultimately down to commercial availability of the required starting material.

Comparing the $\mathrm{EC}_{50}$ values of $\mathrm{I} 3 \mathrm{C}$ and $\mathbf{1 3}$ (entries 3 and 11), reveals there is no clear superior compound, with I3C having better activity against the U251 and IN1528 cultures and compound 13 having marginally better activity against the IN1760 cell culture, however, taken on balance, compound $\mathbf{1 3}$ does appear slightly less effective overall than the parent compound.

\section{The effect of diindolylmethanes}

The final comparison within this series was to investigate the necessity of using the prodrug at all. It is known that the metabolism of I3C to DIM doesn't occur in quantitative yields in 
vitro, so one might assume that by testing the isolated active dimers, activity would increase in parallel with the increase in bioavailability of the active species $\left(\operatorname{cLogP}_{\mathrm{I} 3 \mathrm{C}}=1.43\right.$; $\left.\operatorname{cLog}_{\text {DIM }}=4.20\right){ }^{20}$

To investigate this hypothesis and the necessity of using the prodrugs (I3C and 2) at all, dimers 6 and 14 were evaluated.

The $\mathrm{EC}_{50}$ values for 2, I3C (3), DIM (6) and compound 14 (entries 2, 3, 5 and 12) show some convincing trends. Despite the significantly reduced solubility of DIM compared to I3C, and the complex mechanism of $\mathrm{I} 3 \mathrm{C}$ uptake, ${ }^{17}$ the isolated active compound $\mathbf{1 4}$ has markedly higher anticancer activity than its prodrug 2 against the resistant IN1760 cell culture.

What is particularly interesting is that compound $\mathbf{1 4}$ has higher activity than DIM in all three glioblastoma cultures tested. It was initially assumed that the role of the 2-phenyl group in compound 2 was to aid in the formation of the diindolylmethane metabolite. However, the higher activity of compound $\mathbf{1 4}$ compared to DIM indicates that the 2-phenyl group has a beneficial effect on the active form of the drug as well. This isn't entirely unexpected, as a number of 2-phenylindoles are known to have activities in a wide variety of therapeutic areas. $^{21}$

What is also noteworthy is the considerable improvement of both diindolylmethanes (but especially compound 14) against the chemoresistant IN1760 culture. This is of particular interest as it suggests that this class of compounds not only have reasonable activity against the established cell line U251, they may also have a broad spectrum of activity against otherwise chemoresistant cells. Since IN1760 is considered by groups that work with such short term cultures to be a particularly chemoresistant culture, ${ }^{22}$ analogue 14 may turn out to be a useful fragment against chemoresistant tumours upon further optimisation.

A total of five structural features were investigated as part of this work, and unsurprisingly, the key structural feature of the prodrug form was the 3-carbinol group, as has been seen in other cancers. ${ }^{8-11,16,17,19,23,24}$ Presumably, without this group the active form of the drug could not form. The nitrogen of the indole core also appears to be important, since replacing this 
scaffold with a benzothiophene scaffold, as in compound 13, drastically reduced activity against certain cell lines. $N$-substituted analogues of the prodrug appear to be a viable way of affecting a significant change in activity, with the $N$-tosyl substituent (compound 11) appearing to improve activity. ${ }^{19}$

The 2-phenyl group consistently showed an improvement in activity both in the prodrug and active form of the drug ( $\mathbf{2}$ and $\mathbf{1 4}$, entries 2 and 12), a structural feature which should be included as standard in any future work.

Overall, the most promising compound of this series is compound 14. Since it was shown that $\mathrm{N}$-substituents have a significant effect on the activity of I3C, $\mathrm{N}$-substituted analogues of diindolylmethane 14 will be investigated in due course.

\section{Acknowledgements}

The authors would like to thank the Sydney Driscoll Neuroscience Foundation and Brain Tumour North West for funding and the EPSRC UK National Mass Spectrometry Facility (NMSF), Swansea for accurate mass measurements.

References and notes

(1) Brodbelt, A.; Greenberg, D.; Winters, T.; Williams, M.; Vernon, S.; Collins, V.P.; UK National Cancer Information Network Brain Tumour Group. Eur. J. Cancer 2015, $51,4.533-42$.

(2) Stupp, R.; Mason, W. P.; van den Bent, M. J.; Weller, M.; Fisher, B.; Taphoorn, M. J. B.; Belanger, K.; Brandes, A. A.; Marosi, C.; Bogdahn, U.; Curschmann, J.; Janzer, R. C.; Ludwin, S. K.; Gorlia, T.; Allgeier, A.; Lacombe, D.; Cairncross, J. G.; Eisenhauer, E.; Mirimanoff, R. O.; Van Den Weyngaert, D.; Kaendler, S.; Krauseneck, P.; Vinolas, N.; Villa, S.; Wurm, R. E.; Maillot, M. H. B.; Spagnolli, F.; Kantor, G.; Malhaire, J. P.; Renard, L.; De Witte, O.; Scandolaro, L.; Vecht, C. J.; Maingon, P.; Lutterbach, J.; Kobierska, A.; Bolla, M.; Souchon, R.; Mitine, C.; Tzuk-Shina, T.; Kuten, A.; Haferkamp, G.; de Greve, J.; Priou, F.; Menten, J.; Rutten, I.; Clavere, P.; Malmstrom, A.; Jancar, B.; Newlands, E.; Pigott, K.; Twijnstra, A.; Chinot, O.; Reni, M.; Boiardi, A.; Fabbro, M.; Campone, M.; Bozzino, J.; Frenay, M.; Gijtenbeek, J.; Brandes, A. A.; Delattre, J. Y.; Bogdahn, U.; De Paula, U.; van den Bent, M. J.; Hanzen, C.; Pavanato, G.; Schraub, S.; Pfeffer, R.; Soffietti, R.; Weller, M.; Kortmann, R. D.; Taphoorn, M.; Torrecilla, J. L.; Marosi, C.; Grisold, W.; Huget, P.; Forsyth, P.; Fulton, D.; Kirby, S.; Wong, R.; Fenton, D.; Fisher, B.; Cairncross, G.; Whitlock, P.; Belanger, K.; Burdette-Radoux, S.; Gertler, S.; 
Saunders, S.; Laing, K.; Siddiqui, J.; Martin, L. A.; Gulavita, S.; Perry, J.; Mason, W.; Thiessen, B.; Pai, H.; Alam, Z. Y.; Eisenstat, D.; Mingrone, W. New England Journal of Medicine 2005, 352, 987.

(3) Prabhu, S.; Akbar, Z.; Harris, F.; Karakoula, K.; Lea, R.; Rowther, F.; Warr, T.; Snape, T. Bioorg. Med. Chem. 2013, 21, 1918.

(4) Christopher Sherer, PhD Thesis, University of Central Lancashire, 2016.

(5) Murillo, G.; Mehta, R. G. Nutrition and Cancer-an International Journal 2001, 41, 17.

(6) Grose, K. R.; Bjeldanes, L. F. Chem. Res. Toxicol. 1992, 5, 188.

(7) Weng, J. R.; Tsai, C. H.; Kulp, S. K.; Chen, C. S. Cancer Lett. 2008, 262, 153.

(8) Bradlow, H. L. In Vivo 2008, 22, 441.

(9) Howells, L. M.; Gallacher-Horley, B.; Houghton, C. E.; Manson, M. M.; Hudson, E. A. Mol. Cancer Ther. 2002, 1, 1161.

(10) Hudson, E. A.; Howells, L. M.; Gallacher-Hofrley, B.; Fox, L. H.; Gescher, A.; Manson, M. M. BMC Cancer 2003, 3.

(11) Chinni, S. R.; Li, Y. W.; Upadhyay, S.; Koppolu, P. K.; Sarkar, F. H. Oncogene 2001, 20, 2927.

(12) Nachshon-Kedmi, M.; Yannai, S.; Haj, A.; Fares, F. A. Food and Chemical Toxicology 2003, 41, 745 .

(13) Verhoeven, D. T. H.; Verhagen, H.; Goldbohm, R. A.; vandenBrandt, P. A.; vanPoppel, G. Chemico-Biological Interactions 1997, 103, 79.

(14) Guo, W.; Wu, S. H.; Wang, L.; Wei, X. L.; Liu, X. Y.; Wang, J.; Lu, Z. M.; Hollingshead, M.; Fang, B. L. Plos One 2011, 6.

(15) Huang, X.; Cao, M. R.; Wang, L.; Wu, S. H.; Liu, X. Y.; Li, H. Y.; Zhang, H.; Wang, R. Y.; Sun, X. P.; Wei, C. M.; Baggerly, K. A.; Roth, J. A.; Wang, M.; Swisher, S. G.; Fang, B. L. Oncotarget 2015, 6, 345.

(16) Jellinck, P. H.; Forkert, P. G.; Riddick, D. S.; Okey, A. B.; Michnovicz, J. J.; Bradlow, H. L. Biochemical Pharmacology 1993, 45, 1129.

(17) Staub, R. E.; Feng, C. L.; Onisko, B.; Bailey, G. S.; Firestone, G. L.; Bjeldanes, L. F. Chemical Research in Toxicology 2002, 15, 101.

(18) It should be noted that the more conjugated compound (2) spontaneously decomposes in weakly acidic $\mathrm{CDCl}_{3}$

(19) Weng, J.-R.; Tsai, C.-H.; Kulp, S. K.; Wang, D.; Lin, C.-H.; Yang, H.-C.; Ma, Y.; Sargeant, A.; Chiu, C.-F.; Tsai, M.-H.; Chen, C.-S. Cancer Research 2007, 67, 7815. 
(20) http://www.molinspiration.com/

(21) Lal, S.; Snape, T. J. Curr. Med. Chem. 2012, 19, 28, 4828-4837.

(22) Personal communication with Professor Tracy Warr.

(23) Lerner, A.; Grafi-Cohen, M.; Napso, T.; Azzam, N.; Fares, F. Journal of biomedicine \& biotechnology 2012, 2012, 256178.

(24) Weng, J.-R.; Tsai, C.-H.; Omar, H. A.; Sargeant, A. M.; Wang, D.; Kulp, S. K.; Shapiro, C. L.; Chen, C.-S. Carcinogenesis 2009, 30, 1702. 


\section{Graphical Abstract}

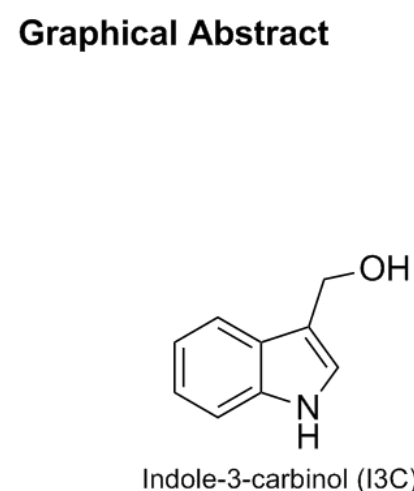

Indole-3-carbinol (I3C)

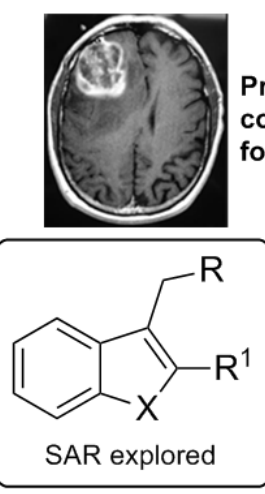

Promising new anticancer

compounds against resistant

forms of glioblastoma<smiles>c1ccc2c(Cc3c[nH]c4ccccc34)c[nH]c2c1</smiles>

3,3'-DiindolyImethane (DIM) -

a metabolite of I3C 